\title{
ADOÇÃO POR PARES DO MESMO SEXO: CONSIDERAÇÕES JURÍDICAS E A OBSERVÂNCIA AOS PRECEITOS CONSTITUCIONAIS E A LEI N\&\#730;8.069/90
} (ECA)

\author{
ADOPTION IN THE SAME SEX COUPLES : LEGAL CONSIDERATIONS AND \\ COMPLIANCE TO PRECEPTS CONSTITUTIONAL AND THE LAW N\&\#730;8.069 \\ 190 (ECA)
}

${ }^{1}$ Leyde Aparecida Rodrigues dos Santos
${ }^{2}$ Zeima da Costa Satim Mori

\section{RESUMO}

O presente estudo tem por objetivo fundamentar a adoção por casais homoafetivos, por meio de preceitos constitucionais, Lei $\mathrm{n}^{\circ}$ 8.069, de 13 de Julho de 1990 Estatuto da Criança e do Adolescente (ECA) e embasamento doutrinário. A evolução natural dos costumes da sociedade nos últimos anos reflete a temática desse estudo que aborda o novo perfil de família com a adoção por casais homoafetivos. Há controvérsias sobre a matéria, contudo a legislação pátria não faz qualquer referência sobre a orientação sexual do adotando, o que pode ser entendido que uma pessoa pode adotar independentemente da sua opção sexual, com base no princípio do melhor interesse da criança ou adolescente e vistas ao princípio da dignidade humana.

Palavras-chave: Adoção, Casais, Dignidade humana, Família, Homoafetivos, Isonomia

\begin{abstract}
This study aims to support the adoption by homosexual couples, through constitutional provisions, Law No. 8069 of July 13, 1990 - Statute of Children and Adolescents (ECA) and doctrinal foundation. The natural evolution of society's customs in recent years reflects the theme of this study that addresses the new family profile with the adoption by homosexual couples. There is controversy on the subject, however the Brazilian legislation makes no mention of the sexual orientation of adopting, which can be understood that a person can adopt regardless of their sexual orientation, based on the principle of the best interests of the child or adolescent and views the principle of human dignity.
\end{abstract}

Keywords: Adoption, Couples, Human dignity, Family, Homosexual, Equality

\footnotetext{
${ }^{1}$ Mestra pelo Programa de Mestrado em Direito pelo Centro Universitário Salesiano São Paulo - UNISAL, São Paulo, SP (Brasil).E-mail.: audmed2008@ hotmail.com

${ }^{2}$ Mestranda do Programa de Mestrado em Centro Universitário Salesiano - UNISAL, São Paulo, SP, (Brasil). Professora do Centro Universitário Salesiano São Paulo, UNISAL, São Paulo.(Brasil). E-mail.: zeimasatim@yahoo.com.br
} 


\section{INTRODUÇÃO}

Na contemporaneidade se vive a era dos direitos humanos, em que os direitos, a igualdade e a liberdade estão pautados como substanciais à dignidade da pessoa humana.

Existe hoje a preocupação com a inclusão social do ser humano em sua sociedade, basilarmente na esfera da tutela de direitos e garantias fundamentais. Em se tratando da vulnerabilidade das minorias, existe uma preocupação maior.

Nesse diapasão e como tema desse estudo, surge a discussão acerca da possibilidade da adoção homoafetiva. Contrário a esse cenário há o argumento que a criança ou adolescente adotada por casais homoafetivos, pode ser influenciada na orientação sexual, ensejando a opção pela homossexualidade futuramente. Nessa corrente contrária, acrescentam ainda, que tais adotados, seriam vistos pela sociedade com a figura de duplicidade paterna ou materna, viabilizando a possibilidade da criança sofrer discriminações.

Contudo, não há legislação brasileira que ampare a adoção homoafetiva, mesmo concernente àqueles que possuam uma união estável, caracterizada como sólida e duradoura baseada no respeito e na fidelidade.

Ante a ausência de disposição legal na matéria, esse direito aludido pelos casais homossexuais, fica a mercê de decisões judiciais que ainda expressam certa resistência ao tema, ou seja, o direito dos homoafetivos de gozarem do instituto da adoção.

Apesar da lacuna da Lei em normatizar o tema, já existem julgamentos viabilizando a adoção homoafetiva. As supracitadas decisões se pautam na observância aos princípios fundamentais da dignidade da pessoa humana, a igualdade e o melhor interesse da criança e adolescente para justificar esse direito.

Oportuno comentar que o Estatuto da Criança e do Adolescente (ECA), autoriza a adoção por uma pessoa em singular sem qualquer menção quanto a sua orientação sexual, o que de direito, a pessoa homossexual pode camuflar a sua preferência sexual para pleitear a adoção. Entretanto, tal procedimento oculta a verdade, e tanto o parceiro (a) do adotante como a criança adotada, não podem desfrutar juridicamente do vínculo construído.

Levando-se em consideração todas as argumentações que dizem respeito a essa temática, o presente artigo tem por objetivo, analisar a possibilidade de reconhecimento legal de adoção por pares homoafetivos a uma criança que sem pais ou sem lar afetivo, possa ter uma família com a melhor formação moral, social e econômica, atentando no hegemônico interesse da criança ou adolescente. 


\section{FAMÍLIA, REGRAS E PRINCÍPIOS}

No sistema jurídico brasileiro os princípios constitucionais são considerados basilares e em uma releitura dos institutos e normatização do Direito de Família, pode-se observar que o preenchimento de lacunas deixou de ser complemento e de possuir apenas força supletiva para ganhar uma eficácia normativa imediata.

Os ensinamentos doutrinários expressam que na lacuna da Lei, o juiz não deve se eximir de julgar e sim fazer uso de analogia, costumes e princípios gerais do direito afim da melhor solução para o conflito.

Peres (2006, p. 97-98) aduz em seus estudos que há diferença entre regras e princípios. Segundo a autora, existe a diferença quantitativa que caberá ao intérprete no caso concreto identificar se está diante de um princípio ou uma regra. E há a diferença de grau e no ponto de vista estrutural e lógico, pois quando se trata de regras, elas podem ou não reger uma determinada situação.

Nos tempos atuais, os direitos fundamentais justificam a cidadania concomitante com os princípios gerais de proteção da família, dentre os quais: princípio da dignidade da pessoa humana, princípio da afetividade e solidariedade. Princípios esses que consistem na proteção das minorias.

Assim os princípios devem ser ponderados em concordância com as regras a fim de encontrar a melhor forma de solucionar os conflitos em concreto. Nesse estudo, o conflito em questão compreende a estrutura familiar.

Peres (2006, p. 22) faz menção a duas teorias básicas da família: a matriarcal que é baseada na ideia de que a família foi originária de um estágio inicial de promiscuidade e a patriarcal, ou seja, o pai sempre foi o núcleo da estrutura familiar, e com isso nega o período inicial de promiscuidade.

Oportuno mencionar que houve uma evolução nos modelos de família e na atualidade diversas formas de agrupamento familiar foram se constituindo.

No passado a família era numerosa, formada pelos pais, a grande prole, parentes e os agregados, embora os direitos fossem somente dos progenitores em matrimonio.

Com o passar do tempo, a mulher passou a crescer profissionalmente no mercado de trabalho e muitas vezes havendo trocas de papéis dos cônjuges no sustento do lar e por consequência poder isonômico da estrutura familiar.

Assim com a transformação evolutiva, além da família tradicional formada pela constituição do casamento entre homem e mulher, surge o ingresso de novos costumes e 
valores concomitantes com a globalização, a internacionalização de direitos humanos, a atenção e referência ao ser humano em vista da sua dignidade.

Nesse cenário a pós-modernidade veio remodelar as relações familiares, respeitando as diferenças que dispõem os seres humanos.

\subsection{MUDANÇAS NO MODELO FAMILIAR NA PÓS-MODERNIDADE}

Diferentes núcleos familiares surgiram nos últimos anos. No passado o poder familiar era exclusivo patriarcal. Atualmente houve uma mudança de mentalidade da sociedade fazendo surgir novas composições de família.

Família na Constituição Federal e no Código Civil a princípio é considerada família matrimonial e com a modernidade e alteração dos costumes houve uma modificação na conceituação de família, como: a união estável, protegida pela Constituição Federal no artigo 226 e seguintes.

Fachin, (2003.p.1) narra em seu estudo: "Afastando-se dos laços formais, são valorizadas as relações de mútua ajuda e afeto, com índices cada vez maiores de uniões não matrimonializadas".

O fato é que o vínculo familiar presente nos Documentos Legislativos pátrios vem-se modelando por meio de outras formas de relacionamento duradouro e efetivo, baseado no afeto, no cuidado, que vem ganhando reconhecimento legal em vários países do mundo, afim de que a valoração dos direitos humanos e respeito pelas diferenças ganhe destaque no cenário legislativo.

\subsubsection{FAMÍLIA MATRIMONIAL}

O matrimônio monogâmico é à base da origem da estrutura familiar.

Não obstante a influência do Cristianismo no instituto, a antiguidade greco-romana preparou solidamente as bases da sociedade para a prática milenar da família monogâmica que se conhece... embora cada vez mais se busque, dentro da evolução social a que se assiste, o equilíbrio do homem e da mulher na relação conjugal, em cujo fundamento se prevê uma sobreposição do interesse social sobre o interesse individual. (DANTAS, 1991, p. 13-14)

Assim, dentre os fins da instituição da família matrimonial o casamento é originário das inter-relações existentes entre marido e mulher ou homem e mulher e com a prole, entre 
pais e filhos. É o que preconiza o artigo 1.514 do Código Civil: "O casamento se realiza no momento em que o homem e a mulher manifestam, perante o juiz, a sua vontade de estabelecer vínculo conjugal, e o juiz os declara casado".

Monteiro e Silva, (2009, p.23) apresentam um conceito de casamento no qual origina a família matrimonial. Senão vejamos:

\begin{abstract}
Casamento é a união permanente entre o homem e a mulher, de acordo com a lei, a fim de se reproduzirem, de se ajudarem mutuamente e de criarem os seus filhos... a reprodução não é mais a finalidade precípua do casamento, devido ao fato de que muitos casais optam por não ter filhos, mas o mútuo adjutório sim, sempre foi e será não só a finalidade, mas o efeito jurídico do casamento.
\end{abstract}

Oportuno comentar, que o artigo 226 da Constituição Federal de 1988, cristaliza a família como vínculo jurídico entre homem e mulher como base da sociedade, com especial proteção do Estado, em vista do parágrafo $1^{\circ}$ que preconiza a gratuidade da celebração do casamento civil. $^{1}$

Nessa tela, a família matrimonial, é a que tem como origem, o casamento composto pelos cônjuges e prole.

Entretanto, conforme Bittar (2003, p. 63), a estrutura familiar formada no casamento foi se alterando com a evolução dos tempos. A Constituição Federal Brasileira proclama a igualdade de direitos entre homem e mulher na sociedade conjugal, rompendo com todas as regras discriminatórias.

\title{
1.1.2 FAMÍLIA MONOPARENTAL
}

Composta por apenas um dos progenitores: pai ou mãe. Observa-se espécie de família que tem aumentado nas últimas décadas. É uma tipologia familiar que se origina por vários motivos circunstanciais que viabilizam esta estrutura: crises no relacionamento que resultam em divórcios ou abandono do lar por parte de um dos cônjuges, falecimento de um dos cônjuges, ou ainda a decisão de ter um filho independente.

No espaço da pluralidade familiar tem assento a família não matrimonializadas. Nesse ninho sem moldura apresenta-se ao lado da união estável, o concubinato e a monoparentalidade. Tem-se que a união estável aproxima-se muito do casamento, em cuja conversão pode ser facilitada, a união livre corresponde a uma união

\footnotetext{
${ }^{1}$ Nos termos de Maria Helena Diniz, a "concepção institucionalista vê no matrimônio um estado em que os nubentes ingressam. O casamento é tido como uma grande instituição social, refletindo uma situação jurídica que surge da vontade dos contraentes, mas cujas normas, efeitos e forma encontram-se preestabelecidas pela lei. As partes são livres, podendo cada uma escolher o seu cônjuge e decidir se vai casar ou não (...)”. (grifo original). Ver: Curso de direito civil brasileiro, volume 5: direito de família. $24^{\text {a }}$. ed. reformulada. São Paulo: Saraiva, 2009, p. 41
} 
informal não suscetível de conversão, e a família monoparental a que se funda o vínculo de um dos pais e sua prole. (FACHIN, 2003.p. 92-93)

Em síntese a família monoparental é, pois constituída por um só cônjuge e seus filhos independente da idade.

\subsubsection{FAMÍLIA CONTEMPORÂNEA}

Com a evolução de costumes e valores, caracteriza-se pela inversão dos papéis do homem e da mulher no vínculo familiar. A mulher passa a ser a chefe de família. Compõe-se como a família monoparental, constituída por mãe solteira ou divorciada.

O conflito se manifestou com a busca da individualidade e a livre escolha. "As pessoas querem aprender, ao mesmo tempo, a serem sós e a "serem juntas."” (SARTI, 2006, p.43).

Com a modernização as mulheres estudaram e se prepararam para enfrentar o mundo do trabalho e se especializaram em diversas profissões. Ocupam atividades no mercado de trabalho que antes eram somente exercidas por homens.

A contemporaneidade trouxe a possibilidade de escolha da maternidade. Com essas conquistas das mulheres em optar pela maternidade e ao mesmo tempo se envolver no mercado de trabalho, surgem novas recomposições e com o advento de situações cotidianas, nasce um novo padrão dominantes de casamento e núcleo familiar.

Cada vez mais as pessoas estão buscando a realização e a felicidade. Com a modernidade as pessoas passaram a ter mais coragem de assumir suas escolhas e optar por relacionamentos que lhes tragam mais prazer e realização. Como a infelicidade na vida matrimonial e familiar não escolhe pessoas por causa de sua classe social, etnia e por sua opção religiosa, também nas comunidades religiosas observam-se, cada vez mais, diversas configurações familiares. (WIRTH, 2013, p. 4)

A família contemporânea surge com outros padrões e a família tradicional passou por mudanças no protótipo e acima de tudo com o rompimento ou não de velhos paradigmas.

$\mathrm{O}$ que antes era aceito pela sociedade como uma concepção do núcleo familiar constituída por pai, mãe e filhos não se vê atualmente como um modelo único.

\subsubsection{FAMÍLIA HOMOSSEXUAL OU FAMÍLIA HOMOAFETIVA}

Nos termos de Rios (2001, p.110), em atenção ao princípio da dignidade da pessoa humana, as relações entre pessoas do mesmo sexo estão inseridas no âmbito jurídico, e, portanto não existe razão para a exclusão.

Dispõe a Constituição Federal a proteção à família no artigo 226, "a família, base da sociedade, tem especial proteção do Estado". No parágrafo $3^{\circ}$ do mesmo artigo estendeu essa 
proteção à união estável, e em seu parágrafo $4^{\circ}$ expandiu sua proteção também à família monoparental, um dos modelos de vínculo não reconhecidos pelo matrimônio. Contudo, não foi estendida essa proteção aos homossexuais, que na atualidade já estão avançando nessa questão.

A releitura do artigo 226 da Constituição Federal consistia como reconhecimento de união estável e, portanto entidade familiar apenas os casamentos entre casais heterossexuais.

As uniões homossexuais compreendem relações familiares semelhantes com o casamento. A diferença diz respeito à possiblidade de gerar filhos. (DIAS, 2011, p. 80).

A família formada por pessoas do mesmo sexo são denominadas família homoafetiva. $^{2}$

Oportuno comentar que a homossexualidade durante décadas passou a ser encarada como um desvio, um fato social atípico e não aceitável pela sociedade, principalmente a partir da ascendência cristã, que em tempos remotos afirmava que a homossexualidade era um "vício de caráter que deveria ser afastado por todos aqueles que desejassem viver no reino dos céus.” (MARTINS, 2010).

Sendo assim, até a pouco tempo a união homoafetiva não era reconhecida, era um vínculo que existia, entretanto não validado perante o ordenamento jurídico.

Foi necessário para a regulamentação desse vínculo familiar que o Supremo Tribunal Federal reconhecesse o casamento entre homossexuais por meio da Ação Direta de Inconstitucionalidade (ADI) 4277 e da Arguição de Descumprimento de Preceito Fundamental (ADPF) $132^{3}$. A primeira reconheceu a união entre pessoas do mesmo sexo como entidade familiar, sendo assim os direitos e deveres seriam os mesmos dos casais heterossexuais; e a segunda julgou que o não reconhecimento da união homoafetiva, violava os conceitos fundamentais como: liberdade, igualdade e o princípio da dignidade humana presentes na Constituição Federal ${ }^{4}$.

Foi um marco para história a partir da interpretação constitucional o reconhecimento jurídico da união entre pessoas do mesmo sexo como entidade familiar, ampliando o conceito de família, com base na isonomia dos princípios constitucionais.

\footnotetext{
${ }_{3}^{2}$ A terminologia família homoafetiva, foi firmada por Maria Berenice Dias.

STF - AÇÃO DIREITA DE INCONSTITUCIONALIDADE: ADI 4277/DF - Disponível em <http:stf.jusbrasil.com.br/jurisprudência/20627236/acao-direta-de-inconstitucionalidade-adi-4277-df-stf> Acesso em: 08 ago 2015.

4 Importante mencionar que estiveram presentes no julgamento 10 ministros. Entretanto o Ministro Dias Toffoli se declarou suspeito, uma vez que foi Advogado Geral da União em 2008.
} 
Ambas as ações se basearam no artigo 1.723 do Código Civil brasileiro e sua interpretação conforme a Constituição. Eis a postura do Relator Ministro Ayres Britto que evidenciou pela procedência de ambas as ações:

E, de logo, verbalizo que merecem guarida os pedidos formulados pelos requerentes
de ambas as ações. Pedido de "interpretação conforme à Constituição" do
dispositivo legal impugnado (art. 1.723 do Código Civil), porquanto nela mesma,
Constituição, é que se encontram as decisivas respostas para o tratamento jurídico a
ser conferido às uniões homoafetivas que se caracterizem por sua durabilidade,
conhecimento do público (não-clandestinidade, portanto) e continuidade, além do
propósito ou verdadeiro anseio de constituição de uma família. ${ }^{5}$

Sem questionar a legitimidade do Supremo Tribunal Federal, ignorar essa realidade é negar os direitos e deveres das minorias. Dentre os direitos a adoção por homossexuais, questão ainda muito discutida. Há quem diga que adoção por homossexuais causariam problemas psicológicos em seus filhos, já que teria um modelo uma referência comportamental "incorreta" e, portanto teria uma tendência ao homossexualismo.

Outros levantam a hipótese que o próprio adotado teria vergonha de sua origem, sofrendo os preconceitos por parte da sociedade.

Por derradeiro, a adoção a priori por homossexuais não é diferente da adoção por heterossexuais, visto que dar amor, dar afeto, proteger, ensinar valores, é uma capacidade que qualquer ser humano adquire, independente da escolha sexual, entretanto há um impedimento: o preconceito de parte da sociedade.

\section{CONTEXTO DA HISTÓRIA DA ADOÇÃO}

Por se tratar de um dos institutos mais remotos e que emergiu dos costumes de quase todos os povos, o seu conceito varia de conformidade à época e às tradições de cada população. Destarte, possui definições conceituais e finalidades diferenciadas, dependendo do período da história.

Em uma releitura dos conceitos na antiguidade, adotar um filho era ligado à perpetuidade da família, pelo culto religioso, cumprindo à filiação, a continuidade patrimonial, moral e religiosa da família (GIRARDI, 2005, p. 113).

O Código de Hamurabi, emergido por volta do ano 1.700 a.C, é considerado o primeiro documento jurídico a mencionar o instituto da adoção, no capítulo XI, artigos 185 à 193, senão vejamos:

XI - ADOÇÃO, OFENSAS AOS PAIS, SUBSTITUIÇÃO DE CRIANÇA

${ }^{5}$ Voto Ministro Ayres Britto, p.7 
$185^{\circ}$ - Se alguém dá seu nome a uma criança e a cria como filho, este adotado não poderá mais ser reclamado.

$186^{\circ}$ - Se alguém adota como filho um menino e depois que o adotou ele se revolta contra seu pai adotivo e sua mãe, este adotado deverá voltar à sua casa paterna.

$187^{\circ}$ - O filho de um dissoluto a serviço da Corte ou de uma meretriz não pode ser reclamado.

$188^{\circ}$ - Se o membro de uma corporação operária, (operário) toma para criar um menino e lhe ensina o seu ofício, este não pode mais ser reclamado.

$189^{\circ}$ - Se ele não lhe ensinou o seu ofício, o adotado pode voltar à sua casa paterna.

$190^{\circ}$ - Se alguém não considera entre seus filhos aquele que tomou e criou como filho, o adotado pode voltar à sua casa paterna.

$191^{\circ}$ - Se alguém que tomou e criou um menino como seu filho, põe sua casa e tem filhos e quer renegar o adotado, o filho adotivo não deverá ir-se embora. O pai adotivo lhe deverá dar do próximo patrimônio um terço da sua quota de filho e então ele deverá afasta-se. Do campo, do horto e da casa não deverá dar-lhe nada.

$192^{\circ}$ - Se o filho de um dissoluto ou de uma meretriz diz a seu pai adotivo ou a sua mãe adotiva: "tu não és meu pai ou minha mãe", dever-se-á cortar-lhe a língua.

$193^{\circ}$ - Se o filho de um dissoluto ou de uma meretriz aspira voltar à casa paterna, se afasta do pai adotivo e da mãe adotiva e volta à sua casa paterna, se lhe deverão arrancar os olhos.

$194^{\circ}$ - Se alguém dá seu filho a ama de leite e o filho morre nas mãos dela, mas a ama sem ciência do pai e da mãe aleita um outro menino, se lhe deverá convencê-la de que ela sem ciência do pai e da mãe aleitou um outro menino e cortar-lhe o seio.

$195^{\circ}$ - Se um filho espanca seu pai se lhe deverão decepar as mãos. ${ }^{6}$

Assim, o que se constata é que a adoção era uma forma de contrato entre partes e que ambos, adotante e adotado tinham obrigações mútuas e dessa forma a perpetuidade e os anseios pessoais não eram vistos como fundamentais, prevalecendo os laços religiosos.

Neste sentido, atinente a essa história, conforme o pensamento de Rodrigues (2004, p. 335), a última forma de assegurar a continuidade da família e a perpetuação de seu culto, quando não havia a possibilidade de se ter um filho, era pelo instituto da adoção, cabendo aos filhos cultuar as memórias de seus antepassados. Dessa forma, aqueles que não tivessem como fazê-lo possuíam risco de extinção de sua família, por não possuírem formas de cultivar e ramificar suas raízes ancestrais.

Venosa (2003, p. 253) pondera que a adoção constituía um mero recurso para a manutenção do culto da família pela linha masculina, pois o direito sucessório somente era permitido pelos homens.

A história nos mostra que a adoção na Grécia tinha um escopo social e político, sob o prisma de que os cidadãos podiam tanto adotar como serem frutos de adoção. Ora, perfeitamente visualizado que havia o interesse do adotante, do ponto de vista social, político e religioso pela adoção.

Mais notadamente em Atenas, a adoção era um procedimento mais formal, religioso e somente os homens livres maiores de 18 anos podiam adotar. Mulheres não podiam adotar, no entanto poderiam ser adotadas, assim como os homens.

\footnotetext{
${ }^{6}$ Disponível em: <http://www.dhnet.org.br/direitos/anthist/hamurabi.htm> Acesso em: 10 Ago 2015.
} 
No mesmo passo, o Império Romano, sub-rogado aos laços religiosos, admitia que as pessoas pudessem pedir a adoção pela ascendência familiar, entretanto, se não fosse realizada por meio da natureza, a adoção podia ser concretizada, como uma forma de fornecer a família à ascendência, visto que a natureza não podia concretizar (VENOSA, 2003, p. 253).

Conforme Granato (2010, p.38), em Roma a adoção foi mais evidenciada, senão vejamos:

\begin{abstract}
Além da necessidade de se perpetuar o culto doméstico e dar continuidade à família ali a adoção atingiu, também finalidade política, permitindo que plebeus se transformassem em patrícios e vice-versa, como Tibério e Nero, que forma adotados por Augusto e Cláudio, ingressando no tribunado.
\end{abstract}

Girardi (2005, p. 115) partindo dessa assertiva, aduz que há conclusões de que na Idade Média a adoção foi mais compilada e sistematizada juridicamente, sendo em tal período mais expandido essa possibilidade.

No Brasil, antes de passar a vigorar o Código Civil de 1916, a adoção era regida de forma esparsa, não sistematizada. Contudo, com a vigência do aludido Ordenamento Civil, o instituto da adoção foi disciplinado com o sentido de "dar filhos de forma fictícia" com o único objetivo de dar possibilidade para aqueles que não tinham condições de ter um filho (RODRIGUES, 2004, p. 336).

Nos lindes do Código Civil antecessor ao atual, a adoção tem o significado de ato jurídico em que uma pessoa recebe outro, como filho, independentemente de existir entre elas qualquer parentesco consanguíneo ou afim.

Dias (2011, p. 426), divulga em sua obra que a adoção é um ato jurídico em sentido estrito, cuja eficácia está condicionada à chancela judicial, criando um vínculo fíctício de filiação entre pessoas estranhas, análogo ao que resulta da filiação biológica com a geração de direitos e deveres de qualquer filho ao adotado.

Destaca-se que a finalidade da adoção ganhou com o passar do tempo ampla transformação e isto pode ser exaltado, partindo da interpretação do próprio Código Civil de 1916, o qual tinha por escopo possibilitar que um casal sem filhos pudesse ter a chance de criar uma criança e adolescente, como filho, o que posteriormente foi modificada, vislumbrando-se, em outro patamar, o interesse do menor (VENOSA, 2003, p. 316).

Por oportuno, a adoção não se restringe mais tão simplesmente ao bem estar do adotante, satisfazendo as suas necessidades de ter e criar um filho, mas ao interesse da criança e do adolescente, que é adotado, sem contar que para possibilitar o deferimento da adoção, faz-se mister a comprovação das vantagens para o adotado. 
E nesse sentido há um leque de princípios constitucionais e estatutos assecuratórios aos direitos fundamentais e inerentes à criança e adolescente, cujos preceitos devem ser observados, primando-se pelo bem estar do menor e a sua colocação em uma família substituta, que lhe proporcionará um suporte emocional e financeiro para atender as suas necessidades básicas como base essencial a observância ao respeito da criança e do adolescente (RAMOS, 2008, p. 25-26).

Assim, ao passo que a adoção, atualmente, traz uma significância mais ampla do que simplesmente a inserção da criança e do adolescente em uma família substituta, o objetivo da adoção passou a ser a demonstração cabal do melhor interesse da criança, que atenderá ao seu melhor desenvolvimento em todos os sentidos.

$\mathrm{Na}$ atualidade é priorizado o interesse do menor, mas ainda não está descartada a outra justificativa atinente a vontade de uma pessoa que não tem filhos biológicos ou genéticos, de adotar uma criança ou um adolescente, além do interesse de uma criança e adolescente possuir um lar digno de seus direitos (RAMOS, 2008, p. 26).

Diante de todo o declinado pode-se tranquilamente inferir que o fim buscado através da adoção guarda consonância ao oferecimento ao adotado de um seio familiar saudável e propício ao desenvolvimento da criança e do adolescente, já marginalizada e fragilizada pela falta de um lar digno. Busca-se, portanto, uma família que realmente a acolha como seu membro e que tenha condições sociais, psicológicas e econômicas de suprir às suas necessidades, condignas a de um ser humano, ainda em fase de formação.

Por derradeiro, com o advento da Lei 12.010 de 03 de agosto de 2009, intitulada Lei da Adoção, dispõe que todas as adoções passaram a ser regidas pelo Estatuto da Criança e do Adolescente, com algumas ressalvas.

Contudo a Lei tem como propósito a convivência familiar, com enfoque na manutenção da criança e do adolescente em sua família natural ou extensa e adoção que é uma das formas mitigadas do adotado em família substituta.

\section{ADOÇÃO E OS REQUISITOS GERAIS EXIGIDOS ${ }^{7}$}

A Carta Maior de 1988 dispõe em seu artigo 227 sobre o direito da criança e do adolescente à convivência familiar e comunitária e o Estatuto da Criança e do Adolescente

\footnotetext{
${ }^{7}$ O presente estudo, não possui o propósito de tratar do instituto da adoção em si, mas sim da possiblidade de sua aplicação a casais do mesmo sexo. Entretanto, se faz necessário demonstrar aqui nesse tópico, a adoção em geral. Portanto foram restringidos nessa temática apenas os aspectos superficiais em se tratando dos requisitos exigidos para adoção.
} 
disciplina as relações da criança e do adolescente com a sua família de origem ou com uma família substituta, prevendo as situações de guarda, tutela e adoção.

Pois bem, de conformidade ao estabelecido no artigo 227 , parágrafo $6^{\circ}$, da Constituição Federal, o Estatuto, em seu art. 20, estende a todos os filhos, nascidos ou não do casamento ou por adoção, os mesmos direitos e qualificações, vedando expressamente qualquer tipo de discriminação, no que concerne a filiação.

E para que se viabilize o deferimento da adoção de uma criança ou de um adolescente, o adotante deve preencher uma série de requisitos exigidos pela legislação pátria, de caráter objetivo e também subjetivo.

No âmbito subjetivo, faz-se mister que o adotante seja idôneo e apresente reais justificativas para a adoção, ou seja, a expressa vontade de ter um filho (ROSSATO; LÉPORE, 2009, p. 52).

Em contrapartida, também são exigidos critérios objetivos, e nesse ínterim, o artigo 40 do Estatuto da Criança e do Adolescente (ECA) apregoa que o adotando deve contar com a idade máxima de dezoito anos à data do pedido, exceto se já estiver sob a guarda judicial ou sob tutela dos adotantes.

Faz-se amplamente necessário, neste sentido, a abertura de uma dicotomia existente e que paira entre os doutrinadores acerca do limite de idade para aplicação da legislação atinente à adoção.

Granato (2010, p. 73) parte do pressuposto que embora a lei não trate um limite de idade para o pedido de adoção uma vez que o adotando esteja sob a guarda ou tutela é incontestável que o pedido de adoção deve ser feito até os 21 anos de idade, pois caso contrário não há como requer a adoção de um maior, pois cessa a guarda ou tutela.

Contudo, tem-se que acrescentar que a pessoa que contar com dezoito anos ou mais, somente poderá ser adotado com fulcro no Código Civil de 2002 e não mais pelo Estatuto da Criança e do Adolescente, ou seja, se o pedido da adoção for feito no dia imediato após completar o adotando dezoito anos, não mais poderá seguir as regras do ECA, mas sim do Código Civil (GRANATO, ibidem).

Destarte, por tal linha, a adoção não é admitida para maiores de 18 anos, com vistas às leis estatutárias.

Em contrapartida, há uma corrente doutrinária, inclusive, seguida por Rossato e Lépore (2009, p. 43), cujos ditames consolidam que todas as adoções em geral, sejam de 
crianças, adolescentes ou adultos, serão regidas pelo Estatuto, guardadas as particularidade próprias das adoções de adultos. Nessa temática, ocorre a extensão à adoção aos adultos, com base na nova redação dos artigos 1618 e 1.619 do Código Civil, que trata da adoção de crianças e seu regramento pelo Estatuto da Criança e do Adolescente.

Piovesan (2010, p. 337) apregoa com cátedra, que a Constituição Brasileira de 1988, o Estatuto da Criança e do Adolescente e a Convenção sobre os Direitos da Criança (ratificada pelo Brasil em 24-09-1990) introduzem, na cultura jurídica brasileira, um novo paradigma inspirado pela concepção da criança e do adolescente como verdadeiros sujeitos de direito, em condição peculiar de desenvolvimento.

Acrescenta ainda, que este novo paradigma fomenta a doutrina da proteção integral à criança e ao adolescente e consagra uma lógica e uma principiológica próprias voltadas a assegurar a prevalência e a primazia do interesse superior da criança e do adolescente. $\mathrm{Na}$ qualidade de sujeitos do direito em condição peculiar de desenvolvimento, à criança e o adolescente é garantido o direito à proteção especial (PIOVESAN, ibidem).

Outro requisito importante a ser demarcado é a vontade do adotando de ser adotado, principalmente em se tratando de adolescentes, pois quanto aos menores acaba prevalecendo à observância ao Princípio da Proteção Integral.

A doutrina aduz à necessidade de consentimento do adolescente e mesmo a criança deve ser ouvida se concorda ou não com a adoção, embora diferentemente do adolescente, não se vislumbra necessário o seu assentimento.

Granato (2010, p. 108) aduz com propriedade a interpretação do artigo 45 do ECA, referindo que este peca ao se referir em "consentimento", pois a concordância ou discordância não deve representar o deferimento ou indeferimento da adoção, tendo em vista que o menor não tem discernimento para consentir, melhor forma seria a terminologia "oitiva". Assim, a vontade o adotando deve ser levada em consideração para que este integre a nova família, mas não é decisiva para deferir ou indeferir a adoção.

Nessa temática, oportuno citar Piovesan (2010, p. 347) nos seus escritos, que expressa que no caso de necessidade ou continência que determinem o afastamento da criança ou do adolescente da família natural, precede-se à colocação em família substituta, por meio de institutos da guarda, da tutela ou da adoção, observado sempre o interesse prioritário da criança ou do adolescente e os devidos cuidados para que a sua situação na nova família lhe seja adequada ao exercício dos direitos que lhes são reservados pela Lei. 
Ainda com relação ao consentimento dos pais ou do representante legal, o Estatuto afirma em seu artigo $45, \S 1^{\circ}$, que o mesmo será dispensado quando os pais ou representante legal forem desconhecidos ou tenham sido destituídos do poder familiar. Nestes casos, o que tenta priorizar é o "bem estar do menor" agrega Dias (2011, p. 431), diante da vulnerabilidade da pouca idade.

Na situação em que os pais ou representantes legais não observam e não cumprem o seu dever de guarda, mantença e educação dos filhos, os seus respectivos consentimentos não são essenciais para adoção, eis que mesmo que discordem com a adoção, poderão ter seu poder familiar destituído dispensando seus consentimentos (GRANATO, 2010, p.78). Observa-se que mesmo neste caso, ainda faz-se mister o cumprimento do princípio do contraditório, ou seja, a possibilidade de suas manifestações, para que haja a destituição do poder familiar, de conformidade ao artigo $45 \S 1^{\circ}$ do Estatuto.

No tangível à faixa etária do adotante, há a expressa exigência do Estatuto da Criança e do Adolescente da capacidade para adotar, ou seja, 18 anos de idade, diante da redução da capacidade civil conforme os ensinamentos de Dias (2011, p. 429), constante no Código Civil de 2002. Todavia, a diferença entre o adotante e adotando deve ser de 16 anos, diante de expressa determinação do artigo $42, \S 3^{\circ}$ do Estatuto.

Tal patamar de tempo visa a imitar a vida, segundo Dias (2011, p. 430), pois é a diferença em anos para a procriação, contudo admite menos rigidez para a regra, tendo em vista que o pedido de adoção é antecedido de um período de convívio por lapso de tempo que permitiu a constituição da filiação afetiva. Dessa forma, se existente uma convivência com certa duração anterior à adoção, a regra poderá não ser observada integralmente.

Muito importante destacar que para o deferimento da adoção, não se trata de requisito o estado civil do adotante, bastando que o adotante seja maior de 18 anos, com base no aludido artigo 42, do ECA.

O parágrafo $2^{\underline{0}}$ do ECA dispõe: "Para adoção conjunta, é indispensável que os adotantes sejam casados civilmente ou mantenham união estável, comprovada a estabilidade da família". Contudo a Lei 12.010/09 fez uma releitura nesse artigo, tratando da "nova lei de adoção", cujo teor enseja impedimento para adoção em conjunto por homossexuais (GRANATO, 2010, p. 79).

Outro significativo requisito é a necessidade do adotante proceder a um cadastro de caráter obrigatório, o qual tem previsão no artigo 50 do Estatuto, senão vejamos: “A autoridade judiciária manterá, em cada comarca ou foro regional, um registro de crianças e 
adolescentes em condições de serem adotados e outro de pessoas interessadas na adoção". Com a nova redação da Lei 12.010/09, tal cadastro se tornou indispensável. (GRANATO, 2010, p. 80)

Ademais, o $\S 5^{\circ}$ do artigo 50 que trata da criação dos cadastros da adoção vem assegurar que "[...] Serão criados e implementados cadastros estaduais e nacional de crianças e adolescentes em condições de serem adotados e de pessoas ou casais habilitados à adoção." O Conselho Nacional de Justiça para dar efetivo cumprimento à legislação acima aludida instituiu a Resolução 54/08 ${ }^{8}$, com a criação do cadastro Nacional de Adoção, fazendo com que haja uma troca de informações, à nível nacional.

Neste âmbito, a referida Resolução 54/08 consiste em colocar à disposição um banco de dados a nível nacional de informações sobre crianças e adolescentes a serem adotados e os pretendentes à adoção, a fim de esgotar as buscas de habilitados residentes no Brasil antes de se deferir a adoção a uma família estrangeira (Rossato e Lépore, 2009, p. 56), todavia com prioridade à adoção por residentes brasileiros.

Não menos importante, por fim o artigo 197-E do Estatuto da Criança e do Adolescente, que estabelece a ordem cronológica de inscrição no cadastro de pretendentes à adoção.

Granato (2010, p. 87) pondera, neste sentido, que tal providência acaba por mitigar a opção de entrega da criança ou adolescente aos pretendentes que melhor atendam ao interesse da criança. Justifica-se, por derradeiro, que um casal que se encontra em último lugar da fila poderia ser melhores frente aos interesses do menor, fato que conforme o autor tornaria a ordem cadastral incoerente e inobservada.

Fato é que a adoção pode-se comprovar pelas palavras de Fachin (2003, p. 237) ${ }^{9}$ : "trata-se de modalidade de filiação construída no amor, gerando vínculo de parentesco por opção". Em verdade é uma escolha para dar afeto, amor e cuidado a alguém.

\footnotetext{
${ }^{8}$ RESOLUÇÃO CNJ N 54, DE 29 DE ABRIL DE 2008 - institui o Cadastro Nacional de Adoção. Dispõe sobre a implantação e funcionamento do Cadastro Nacional de Adoção. (Publicada no DJ, pág. 1, do dia 08 de maio de 2008) Segundo o artigo 1: "O Conselho Nacional de Justiça implantará o Banco Nacional de Adoção, que tem por finalidade consolidar dados de todas as comarcas das unidades da federação referentes a crianças e adolescentes disponíveis para adoção, após o trânsito em julgado dos respectivos processos, assim como dos pretendentes a adoção domiciliados no Brasil devidamente habilitados". Disponível em: <http://www.tjsp.jus.br/Download/Corregedoria/pdf/resolucao_cnj_54.pdf> Acesso em: 11 ago 2015.

${ }^{9} \mathrm{O}$ autor ainda acrescenta, que "é na adoção que os laços de afeto se visibilizam desde logo sensorialmente, superlativando a base do amor verdadeiro que nutrem entre si pais e filhos" (2003, p. 237-238).
} 


\title{
4. ADOÇÃO POR CASAIS DO MESMO SEXO
}

$\mathrm{Na}$ seara da homossexualidade, uma matéria ainda com muita querela, talvez pelo pré-conceito, ou a discriminação, é o que diz respeito à possibilidade da parentalidade em se tratando de adoção por pessoas do mesmo sexo, ou casal homossexuais.

Em 2011, precisamente em 04 de agosto de 2011, a Ordem dos Advogados do Brasil (OAB), lançou uma cartilha pela Comissão Especial de Direito à Adoção. São perguntas e respostas sobre as leis brasileiras de adoção. As perguntas 140 e 141 da referida cartilha, serão transcritas para a ilustração desse tópico:

140) Uma pessoa solteira de orientação homossexual pode adotar?

R- Em nossa legislação não há regra que proíba a adoção por pessoas de orientação homossexual. Ocorre, porém, que como acontece com o pretendente à adoção, casado ou solteiro, este deverá requerê-la através de processo judicial. Implica afirmar que o desejo da adoção será obrigatoriamente avaliado por profissionais, que farão um levantamento da vida social do adotante. Vale dizer, por fim, que o que impedirá ou permitirá a adoção jamais será a homossexualidade do pretendente, mas, sim, a apresentação dos requisitos legais e processuais que comprovem as reais vantagens para o adotando e a pretensão fundar-se em motivos legítimos. Art. 42, caput, e 43 do Estatuto da Criança e do Adolescente.

Ser solteiro, casado, heterossexual ou homossexual, pode dar a uma criança ou adolescente um núcleo familiar. Não há legislação que dispõe literalmente que homossexuais podem adotar, desde que comprovado a inexistência de incapacidade que possam impedir a adoção, devendo ser fundamentada em motivos reais e não em suposições e discriminações.

\begin{abstract}
141) Um casal homossexual pode adotar conjuntamente?
R- O Supremo Tribunal Federal, ao julgar a ADI 4277 e a ADPF 132 no mês de maio de 2011decidiu pela equiparação da União Homoafetiva à União Estável definida no Artigo 1723 do Código Civil. Com referida equiparação, sendo a união estável reconhecida como necessária para adoção conjunta consoante o Artigo 42 do ECA, o requisito formal passou a existir sendo possível o deferimento do castro/adoção conjunta do casal homoafetivo. Sem prejuízo, caso a caso, deverá passar pelo crivo do juízo competente cada pedido específico, que diante do caso concreto avaliará a possibilidade de concessão do pleito conjunto. Art. $42 \S 2^{\circ}$, do ECA. Art. 1723 do Código Civil; ADI 4277 ADPF 132.
\end{abstract}

Exercer o direito de parentalidade pode ser de forma singular, ou seja, por pessoas solteiras e também por diversas situações: pessoas que desejam adotar o filho do cônjuge ou companheiro ou até o refazimento da vida afetiva com outro companheiro e assim poderem adotar um "filho".

Quando se trata de pares homossexuais, há uma resistência da concessão da adoção conjunta. Nesse cenário, importante mencionar o precursor caso de concessão de guarda a um casal de mulheres homossexuais, com as sábias palavras de Maria Berenice Dias: ${ }^{10}$

10 TJRS, Sétima Câmara Civil, Apelação Cível: 70013801592. Acordam os Desembargadores integrantes da Sétima Câmara Cível do Tribunal de Justiça do Estado, à unanimidade, em negar provimento ao apelo. 
Participaram do julgamento, além do signatário, os eminentes Senhores DESA. MARIA BERENICE DIAS (PRESIDENTE) E DES. RICARDO RAUPP RUSCHEL. Porto Alegre, 05 de abril de 2006. Relator: DES. LUIZ FELIPE BRASIL SANTOS. APELAÇÃO CÍVEL. ADOÇÃ̃O. CASAL FORMADO POR DUAS PESSOAS DE MESMO SEXO. POSSIBILIDADE. Reconhecida como entidade familiar, merecedora da proteção estatal, a união formada por pessoas do mesmo sexo, com características de duração, publicidade, continuidade e intenção de constituir família, decorrência inafastável é a possibilidade de que seus componentes possam adotar. Os estudos especializados não apontam qualquer inconveniente em que crianças sejam adotadas por casais homossexuais, mais importando a qualidade do vínculo e do afeto que permeia o meio familiar em que serão inseridas e que as liga aos seus cuidadores. É hora de abandonar de vez preconceitos e atitudes hipócritas desprovidas de base científica, adotando-se uma postura de firme defesa da absoluta prioridade que constitucionalmente é assegurada aos direitos das crianças e dos adolescentes (art. 227 da Constituição Federal).

\begin{abstract}
É chegada a hora de acabar com a hipocrisia e atender ao comando constitucional de assegurar proteção integral a crianças e adolescentes. Como há enorme resistência de admitir a adoção por um par homossexual, mas não há impedimento a que uma pessoa sozinha adote alguém, resolvendo o casal constituir família, somente um busca a adoção. Não revela sua identidade sexual e no estudo social que é levado a efeito, não são feitos questionamentos a respeito disso. A companheira ou o companheiro não é submetido à avaliação e a casa não é visitada. Via de consequência, o estudo social não é bem feito. Para a habilitação deveria atentar-se a tudo isso, para assegurar a conveniência da adoção.
\end{abstract}

Dessa forma o que deve se levar em apreço para o instituto da adoção é o melhor interesse da criança, importante somente à convivência da criança em um ambiente saudável, afetuoso, tranquilo, harmonioso e duradouro. Ou seja, não se leva em consideração a orientação sexual dos adotandos, pois ao contrário só acarreta afronta a Constituição Federal, no que dispõe o artigo $3^{\circ}$ inciso $4^{\circ}$ que proíbe qualquer forma de discriminação. Nesse contexto, a tese de que homossexuais tem direito à adoção não é afastada.

Ademais, o ECA também, não restringe a adoção homoafetiva, pois não há qualquer menção sobre a orientação sexual do adotante ou estado civil.

Destarte, sendo um direito fundamental de todo cidadão de viver em um ambiente familiar e gozar de uma vida saudável em sociedade, a adoção configura uma forma autêntica de abrigar o melhor interesse da criança e tendo a possibilidade de ter uma nova família ou conhecer a primeira família.

\title{
CONSIDERAÇÕES FINAIS
}

A dignidade da pessoa humana é elemento essencial do Estado Democrático de Direito e sendo assim não há de se falar em qualquer tipo de discriminação ou desrespeito com base na vida pessoal, rechaçando assim a orientação e liberdade sexual do indivíduo.

De nada vale evidenciar a igualdade de todos perante a lei, se não houver a aceitação da pessoa como ela é e trata-la na medida de sua desigualdade.

A sociedade constantemente passa por mudanças com as evoluções e às vezes o retrocesso. Mudam os costumes e valores e cabe aos operadores do Direito acompanhar e se adaptar a essa evolução. 
Com sapiência a Desembargadora Maria Berenice Dias exalta: “A falta de lei nunca foi motivo para a Justiça deixar de julgar ou de fazer justiça. A omissão do legislador não serve de fundamento para deixar de reconhecer a existência de direitos."

$\mathrm{Na}$ lacuna da normatização da adoção homoafetiva, com base nos preceitos constitucionais e princípios gerais do direito, busca na adoção o melhor interesse da criança e do adolescente, afinal adotar de nada interessa a orientação sexual do adotante, e sim o convívio do adotado em um ambiente saudável.

A adoção é meramente um instituto jurídico, involuntário e regulado pelos laços de afinidade e afetividade entre adotante e adotado, sem qualquer vinculação sanguínea. Surge uma nova família, que se torna a referencia familiar definitiva do adotado.

Como em toda questão polêmica, existem correntes doutrinárias e políticas contrárias, projeto de Lei que pretende coibir a adoção homoafetiva, como o proposto pela Deputada Júlia Marinho (PSC-PA) integrante da bancada evangélica da Câmara, que fundamenta que "o reconhecimento jurídico de união homoafetiva não implica automaticamente a possibilidade de adoção por estes casais, matéria que, a toda evidência, dependeria de lei”. "O regramento legal da adoção não se sujeita ao das uniões civis ou ao do casamento. Cuida-se de instituto especial, que visa ao atendimento dos interesses do adotando, não se podendo alegar que sua vedação a casais homossexuais seja discriminação no acesso a um direito", (...). ${ }^{11}$

Eis o princípio da igualdade nos termos do artigo $5^{\circ}$ caput da Constituição Federal: “Todos são iguais perante a lei, sem distinção de qualquer natureza, garantindo-se aos brasileiros e aos estrangeiros residentes no País a inviolabilidade do direito à vida, à liberdade, à igualdade, à segurança e à propriedade, (...)”. Opiniões contrárias, baseadas na discriminação podem conter influências mais psicológicas, sociológicas e religiosas do que necessariamente normativas.

Contudo, vislumbra-se prosperidade à adoção por pares do mesmo sexo, averiguado nas decisões jurisdicionais, efeito da diminuição do pré-conceito obstinado na sociedade, consagrando os princípios em prol da criança e adolescente: da proteção integral e do melhor

Caso em que o laudo especializado comprova o saudável vínculo existente entre as crianças e as adotantes. NEGARAM PROVIMENTO. UNÂNIME. < http://jij.tjrs.jus.br/paginas/docs/jurisprudencia/Adocao_casal_formado_duas_pessoas_mesmo_sexo.html> Acesso em: 11 ago 2015. 
interesse, bem como: os princípios da igualdade, liberdade e da dignidade da pessoa humana, presentes da Constituição Federal de 1998.

Por meio dessa logicidade e sensibilidade em separar as duas questões: homossexualidade e adoção há de se reconhecer que a adoção pode simbolizar a única oportunidade de uma criança ou adolescente em ter um lar com afeto e uma família que ampare o seu desenvolvimento.

11 Disponível em: < http://congressoemfoco.uol.com.br/noticias/deputada-quer-proibir-adocao-por-casalhomoafetivo/> Publicação: 25/03/2015. Acesso em: 11 ago 2015.

\section{REFERÊNCIAS}

BITTAR, Carlos Alberto; BITTAR FILHO, Carlos Alberto. Direito civil constitucional. 3 ed. São Paulo: Ed. Revista dos Tribunais, 2003

BRASIL. Constituição da República Federativa do Brasil de 1988. Disponível em: < http://www.planalto.gov.br/ccivil_03/constituicao/constituicao.htm> Acesso em: 10 ago 2015

. Lei $\mathbf{n}^{\mathbf{0}}$ 12.010/09. Dispõe sobre adoção; altera as Leis $\mathrm{n}^{\text {os }} 8.069$, de 13 de julho de 1990 - Estatuto da Criança e do Adolescente, 8.560, de 29 de dezembro de 1992; revoga dispositivos da Lei $n^{\circ}$ 10.406, de 10 de janeiro de 2002 - Código Civil, e da Consolidação das Leis do Trabalho - CLT, aprovada pelo Decreto-Lei $\mathrm{n}^{\circ} 5.452$, de $1^{\circ}$ de maio de 1943; e dá outras providências. Disponível em: < http://www.planalto.gov.br/ccivil_03/_ato20072010/2009/lei/112010.htm> Acesso em 09 ago 2015.

Adoção
$\underset{\text { Disponível }}{\text { Resolução CNJ no }}$ 54, de 29 de abril de 2008 - institui o Cadastro Nacional de http://www.tjsp.jus.br/Download/Corregedoria/pdf/resolucao_cnj_54.pdf> Acesso em: 09 ago 2015.

CARTILHA. Adoção um ato de amor. OAB/Comissão Especial de Direito à Adoção, 2011. Disponível em: < http://www.oabsp.org.br/comissoes2010/direitoadocao/cartilhas/cartilha_adocao_internet.pdf> Acesso em: 05 ago 2015.

DANTAS, Francisco Clementino de San Tiago. Direito de família e das sucessões. Rev. e atual. por José Gomes Bezerra Câmara e Jair Barros. Rio de Janeiro: Forense, 1991

DIAS, Maria Berenice. Manual de direito das famílias. 8 ed.rev. e atual. São Paulo: Editora Revista dos Tribunais, 2011

FACHIN, Luiz Edson. Curso de direito civil: direito de família. 2 ed. Rio de Janeiro: Renovar, 2003

GIRARDI, Viviane. Famílias Contemporâneas, Filiação e Afeto: A Possibilidade Jurídica da Adoção por Homossexuais. $1^{\circ} \mathrm{ed}$. Porto Alegre: Editora Livraria do Advogado, 2005. 
GRANATO, Eunice Ferreira Rodrigues. Adoção doutrina e prática: com comentários à nova lei de adoção. 2 ed. Curitiba: Juruá, 2010

MARTINS, Priscilla Uchoa. A família homoafetiva e seu legal reconhecimento. In Âmbito Jurídico, Rio Grande, XIII, n.75, abr 2010. Disponível em: <htp://www.ambito-

juridico.com.br/site/index.php?n_link=revista_artigos_leituraEtartigo_id=7336> Acesso em 09 ago 2015.

MONTEIRO, Washington de Barros; SILVA, Regina Beatriz Tavares da. Curso de direito civil. 39 ed. v. 2 São Paulo: Saraiva, 2009

PERES, Ana Paula Ariston Barion. A Adoção por Homossexuais: Fronteiras da Família na Pós-modernidade. Rio de Janeiro: Renovar, 2006

PIOVESAN, Flávia. Temas de Direitos Humanos. 4 ed. São Paulo: Saraiva, 2010.

RAMOS, Caroline Félix. Adoção por casais homoafetivos: a possibilidade jurídica de adoção por casais homoafetivos. Disponível em: <

http://docs.google.com/viewer?a=v\&q=cache:nAP7gAs2X3oJ:portal2.unisul.br/content/navit acontent_/userFiles/File/pagina_dos_cursos/direito_tubarao/monografias_2008a/Caroline_F_1 ix_Ramos.pdf+caroline+ramos+A+POSSIBILIDADE+JUR\%C3\%8DDICA+DE+ADO\%C3 $\% 87 \% \mathrm{C} 3 \% 83 \mathrm{O}+\mathrm{POR}+\mathrm{CASAIS}+\mathrm{HOMOAFETIVOS} \& \mathrm{hl}=\mathrm{pt}-$

$\mathrm{BR} \& \mathrm{gl}=\mathrm{br} \& \mathrm{pid}=\mathrm{bl} \& \mathrm{srcid}=\mathrm{ADGEEShYPcmKUfdBsqYffIVnGIJ}-$

Cz6OsgfQFRUG23iAWHydMJqZevD5E_wKKAVhlOQ1MpSZHNzZLKK0bnuADkFmSlE WTZpgFD_nFes8HMfdAmtZB0mOCE_dU-

5sxyqpTBWKkt67QINu\&sig=AHIEtbQiH6gBEMuW5LVla6ifSIPgkhJBPQ> . Acesso em: 09 ago 2015.

RIOS, Roger Raup. A homossexualidade no Direito. Porto Alegre: Livraria do Advogado, 2001

RODRIGUES, Sílvio. Direito Civil: direito de família: volume 6, 28 ed. ver. e atual. Por Francisco José Cahali; de acordo com o Novo Código Civil. São Paulo: Saraiva 2004.

ROSSATO, Luciano Alves; LÉPORE, Paulo Eduardo. Comentários à lei nacional da adoção- lei 12.010, de 3 de agosto de 2009 e outras disposições legais: Lei 12.003 e Lei 12.004. São Paulo: Editora dos Tribunais, 2009.

SARTI, Cyntia A. Família e individualidade: um problema moderno. In: A Família Contemporânea em Debate. 7 ed. São Paulo: Educ/Cortez Editora, 2006

VENOSA, Silvio Salvo. Direito Civil: Direito de Família. São Paulo: Atlas, 2003.

WIRTH, Noeme de Matos. As novas configurações da família contemporânea e o discurso religioso. Disponível em:

<www.fazendogenero.ufs.br/10/resources/anais/201386090342_ARQUIVO_Noeme> Acesso em: 09 ago 2015. 